\author{
E-ISSN: 2321-9637 \\ Available online at www.ijrat.org
}

\title{
E-Rationing Management System
}

\author{
Prajakta Shinde $^{1}$, Kautubhi Shukla ${ }^{2}$, Shraddha Zagade ${ }^{3}$, V. S. Kumbhar ${ }^{4}$ \\ Department of Electronics and Telecommunication Engineering ${ }^{1,2,3,4}$, Student ${ }^{1,2,3}$ Assistant Professor ${ }^{4}$ \\ Email: shindepraju97@gmail.com ${ }^{1}$, vijayalaxmi.kumbar@pccoer.in ${ }^{4}$
}

\begin{abstract}
The rationing distribution system also called as PDS (Public Distribution System) distributes food to the end users. Here, we have proposed a system E-rationing management system. The existing conventional Ration card system consists of three categories of cards based on the user's income and the information is updated manually which leads to unfair practices. In this system a QR code is initially generated for each new individual user, as a unique identification of that particular user only. The QR code will contain the entire details of the particular user. Similarly the users database is stored which will also be carried by the concern admin person. It will be a smart card that will have QR code which will be scanned by any smart phones every time the person visits the ration shop. The customers details, amount of commodities has been taken and amount remained will be checked after every scanning and be displayed on computers. Further, the required grocery items are selected as per the amount allocated and provided by weighing it through load sensors. This quantity is deducted from total allocated quantity and the data is updated in particular customers account in the system. This discusses strategy to control diversion of items for avoiding malpractices and corruption, for its successful application E-management way. The main objective is to enhance the visibility, transparency, accessibility and efficiency of the system.
\end{abstract}

Index Terms- E-ration card; Quick Response code; load sensor; transparency between government (admin) and consumers; digitized web applications.

\section{INTRODUCTION}

Ration cards issued by government enable users to buy fuel, food, etc at subsidized rates. The existing system consists of a ration book of three categories. The permissible or allocated quantity is decided based on the family income and number of family members. The three categories are below poverty line, above poverty line and card for the poorest of the poor people. There are three different colors allotted for these three categories that are yellow, orange and white. The existing system has some drawbacks. It requires manual work, which is tedious and fraudulent. Sometimes the customers buy extra goods on the name of other people. And also the retailers practice forgery by not selling the required quantity of goods. Hence we go for the proposed system. In this system, we use QR code for authentication purpose. In this system, we provide each customer with a unique QR code after registration. All the details of the customers will be stored in a database. Personal details such as name, address, quantity bought and the quantity remained. There are different login credentials for government who is admin and customers. Customers can get his details by logging into the customer login page. After that scanning of QR code is done. It will ensure the identification of customer. After purchase, database will be automatically updated. The advantages of the proposed system are there is reduced manpower, the limitations of existing system have been overcome and also transparency is maintained between the government and customer.

Author [1] described that the system uses barcodes. It consists of two databases, one for storing user's personal information and other for storing the purchase details. But damaged barcodes cannot be scanned and they need special equipment for scanning. The system is designed by replacing conventional ration card by RFID based smart card reader and interfaced it with ARM. But the drawback is that damaged RFID cards cannot be used [2].

This author described that the system uses RFID card which acts as a ration card and Biometrics. The consumer scans the RFID card and the thumb impression is used for authenticating the consumer [3]. This author described that the system uses biometrics for authenticating the consumer, also the government and local database is updated according to goods supply [4].

This author described that the system uses RFID and GSM technology to send SMS notifications. The drawback for the system is that the RFID cards damaged then the authentication of the person is lost and also the data. [6]

\section{BLOCK DIAGRAM}

The smart E-ration card system is designed for interface between desktop systems, effective GUI and well user friendliness will be major design 


\section{Available online at www.ijrat.org}

considerations. We are utilizing the database to store the various information of the customers which includes their personal details, allotment of grocery items and check of every allotment will be done and be updated every time the customer buys from ration shop.

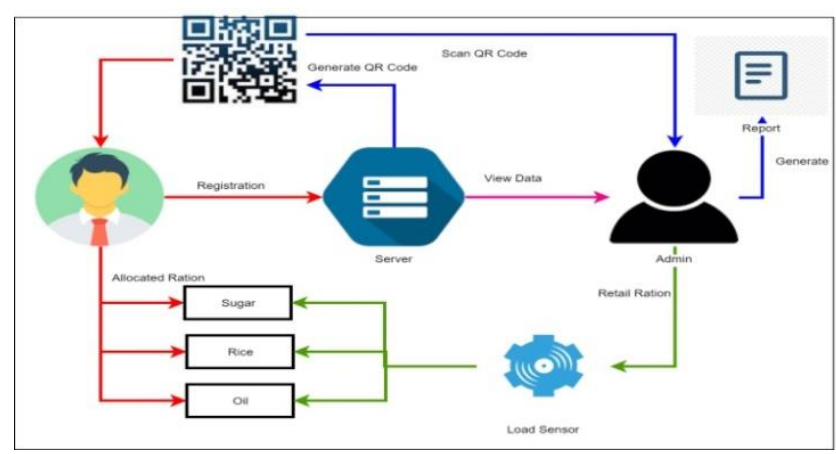

Fig. 1. Block Diagram

In this paper, firstly the user or customer will go through the registration by filling a form including personal details. Then a user ID and password will be generated after the successful registration of the customer, the details will be stored in the database which will be helpful for the admin (government) to maintain and keep the track of his purchase and will be updated in his account accordingly. Then a QR code will be generated which will be always carried by the customer during his purchase. After scanning the QR code, OTP will be generated so as to maintain security to assure the items are gained by the authorized person only. The software system will be interfaced through a controller to interconnect with the Load sensor. This load sensor is used so as to achieve accurate amount of grocery items to the customer directly linked through its database, where it shows the detail of his purchase.

Typeset sub-subheadings in medium face and capitalize the first letter of the first word only.

\subsection{Data flow diagrams}

A data flow diagram (DFD) is a graphical representation of flow of data through an information system, modeling its process aspects [7]-[8]. A DFD is often used as a preliminary step to create an overview of the system. It can also be used for visualization of data processing (structured design). A DFD shows what kind of information will be to the input and output of the system, where the data will come from and go and where the data will be stored. Sections, sub-sections and sub-subsections are numbered in
Italic. Use double spacing before all section headings and single spacing after section headings.

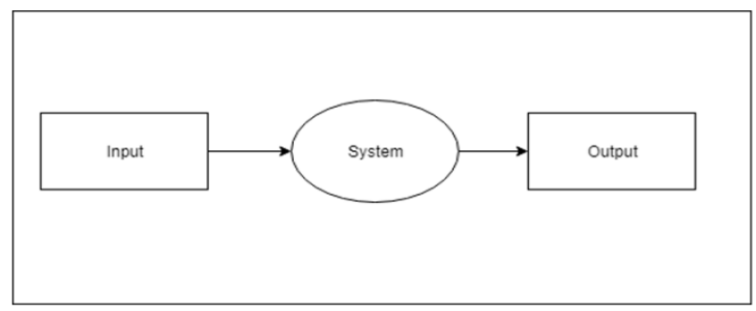

Fig. 2. DFD 0

The DFD 0 figure interprets the input and output interacting to the system which will perform their own functions smoothly.

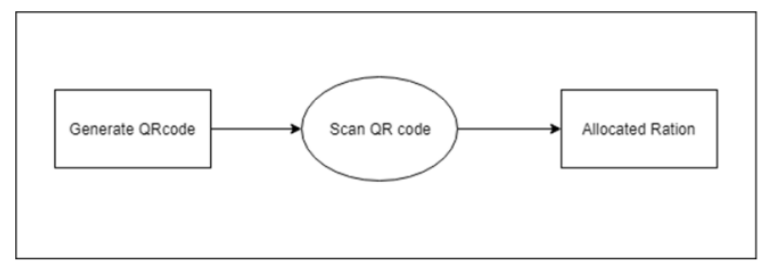

Fig. 3. DFD 1

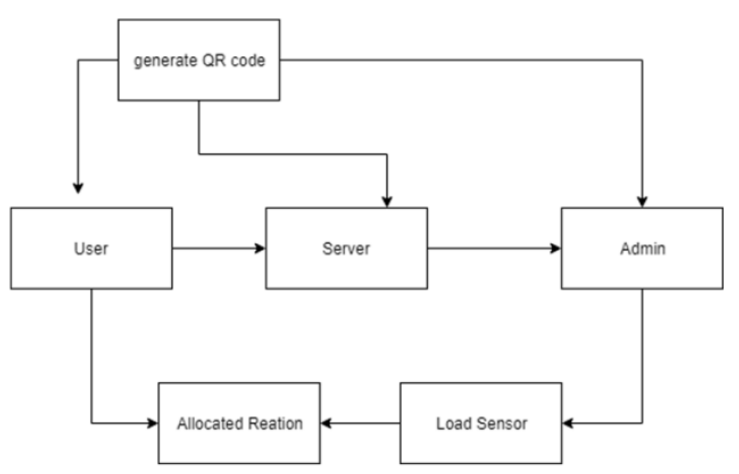

Fig. 4. DFD 2

\section{ENTITY REPRESENTATION DIAGRAM}

An Entity Representation (ER) model defines one of the types of flowchart that illustrates how entities, such as people, objects or concepts are related to each other in a system.

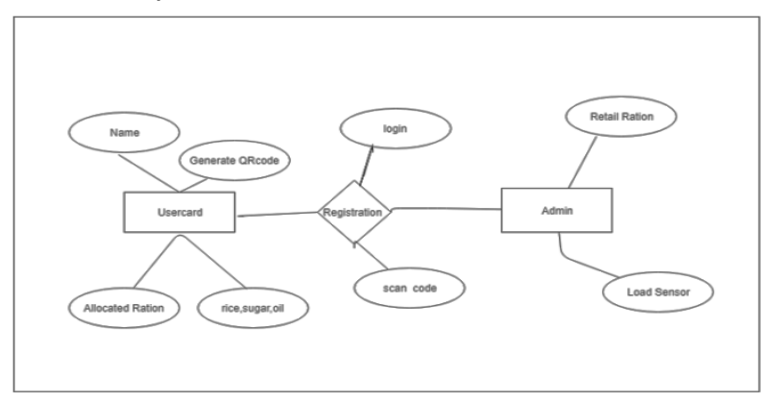

Fig. 5. ER diagram for E-ration card System 


\section{Available online at www.ijrat.org}

The ER diagram consists of two main entities user and admin. Entities are referred to as attributes. All attributes defines the ER model and have values. The user entity is the customer purchasing grocery from ration shop by using E-ration card, while the admin is the government authority to handle the items while assigning to the customer.

At read level, the ER model is taken into account as an honest choice for planning databases.

\section{Conclusion}

This paper contains the existing system and their drawbacks. It has solutions to these drawbacks and detailed working of proposed system using QR code and sms gateaway. This system is very accurate, which is used for real time applications. Thus, on the basis of literature survey and by analyzing the existing system, we have came to a conclusion that the proposed system will not only aid the government agencies but will also help to digitize the system in turn help to deploy resources efficiently to the citizens.

\section{Acknowledgments}

We are gladly taking this opportunity to thank Dr. Prof. Rahul Mapari (Head of Department of Electronics and Telecommunication Engineering) and Project Guide Mrs. V. S. Kumbar for their valuable guidance and providing facility during progress of project. Last but not least we are thankful to all those who help directly or indirectly to develop this project and complete it successfully.

\section{REFERENCES}

[1] Vikram Singh; Vellanki Aamani; Booreddy Mounika (April 2013): Smart Ration Card. Journal of Global Research in Computer Science, Volume 4, No. 4.

[2] A.N.Madur; Sham Nayse (July 2013): Automation in rationing system using ARM7 and RFID. International journal of innovative research in electrical, electronics, instrumentation and control engineering, Volume 1.

[3] Kashinath Wakade; Chidrawar Pankaj; Aitwade Dinesh (April 2015): Smart Ration Distribution Partition and Power Controlling. International Journal of Scientific and Research Inventor Publication, Volume 5, Issue 4.

[4] Yogesh Kumar Sharma; Dr. K. B. Shivakumar; Srinidhi G. (March 2015): Biometric Device using PDS. IRF International Conference.

[5] Besil Issac; Alwina James; Vijethraj S. V. (June 2017): Smart Ration Card using RFID and GSM based Technology. Internatinal Journal of Internet of Things, Volume 6, No. 2.
[6] RS Parbat, SD Mahamine, SH Bodake, MP Aher, "Dual polarized triple band microstrip antenna for GSM/WiMAX/WLAN applications", Automatic Control and Dynamic Optimization Techniques (ICACDOT), PP 1137-1141, [DOI: 10.1109/ICACDOT.2016.7877764].

[7] Rahul Ganpat Mapari, Dr. D. G. Wakde, R. G. Tambe, A. B. Kanase, Shivajirao Patil, "Modeling and Simulation of the Single-Phase Unity Power Factor Active Rectifier for Minimizing the Input Current Harmonic Distortions", Int. Journal of Applied Mechanics \& Material., vol. 267, pp. 9194, (2013).

[8] Rahul Ganpat Mapari, Ajit Kanse, Dr. D B Talange, "Gear shifting using Retrofit Automatic Manual Transmission technique in wind energy conversion system", Proceedings of IEEE/ ISESEE , pp. 1655-1660, (2011). 